\title{
Maternal characteristics in relation to income in a semi-rural community in Pakistan
}

\author{
A.R. Siddiqui ${ }^{1}$ \\ الحُصائص الأمومية وعلاقتها بالدخل في بجتمع شبه ريفي في باكستان \\ آمنة ريخانة صديقي

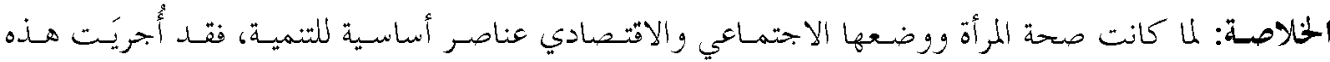

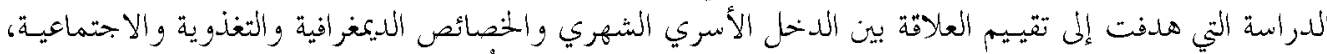

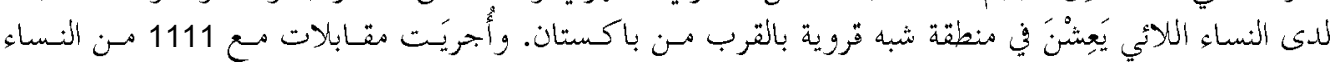

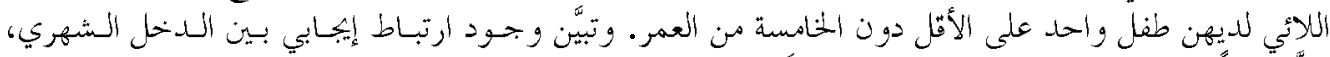

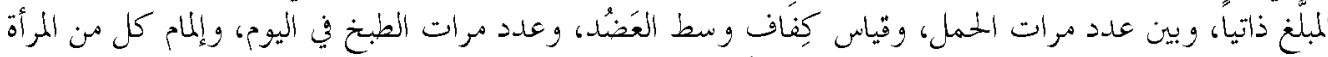

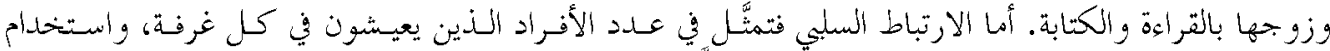

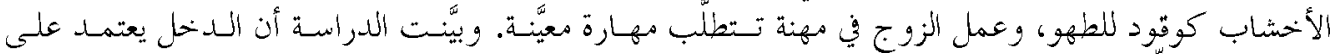

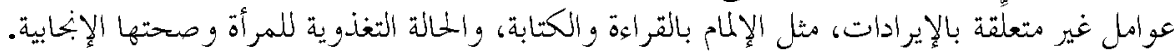

ABSTRACT Women's health and socioeconomic status is fundamental to development. The aim of this study was to evaluate the relationship of monthly household income with demographic, nutritional and social characteristics in women living in a semi-rural location near Karachi. Thus 1111 mothers with at least 1 child under 5 years of age were interviewed. Self-reported monthly income was positively associated with gravidity, mid upper-arm circumference, cooking frequency per day and self and spousal literacy; it was negatively associated with number of occupants per room, wood used as cooking fuel, and spouse in a skilled occupation. Income is dependent on non-income factors such as literacy, and the nutritional and reproductive health status of women.

\section{Caractéristiques maternelles et revenus en zone semi-rurale au Pakistan}

RÉSUMÉ La santé et le statut socio-économique des femmes sont l'une des clés du développement. Cette étude avait pour objectif d'évaluer le rapport entre le revenu mensuel des foyers et les caractéristiques démographiques, nutritionnelles et sociales des femmes résidant en zone semi-rurale près de Karachi. À ce titre, 1111 mères d'au moins un enfant de moins de 5 ans ont été enquêtées. Il est apparu une association positive entre le revenu mensuel autodéclaré et la gravidité, le périmètre brachial à mi-hauteur, la fréquence quotidienne de préparation des repas, le degré d'instruction de la femme et de son conjoint, tandis que cette association s'est révélée négative sous l'angle du nombre d'occupants par pièce d'habitation, de l'utilisation du bois comme combustible de cuisson et de l'emploi du conjoint comme travailleur qualifié. Le revenu est fonction de facteurs indépendants de lui-même, tels que le degré d'instruction et les statuts nutritionnel et reproducteur de la femme.

${ }^{1}$ Department of Community Health Sciences, Aga Khan University, Karachi, Pakistan (Correspondence to A.R. Siddiqui: rehana.siddiqui@aku.edu; arsiddiqui@ucdavis.edu).

المجلة الصحية لشرق المتوسط، منظمة الصحة العالمية، المجلد الثالث عشر، العدد Y، V... 


\section{Introduction}

Initiatives were taken in the year 2000 to work towards achieving the Millennium Development Goals (MDG) by the year 2015. The specific objectives of MDGs are to eradicate extreme poverty and hunger, achieve universal primary education, promote gender equity and empower women, reduce child mortality, improve maternal health, control infectious diseases, ensure environmental sustainability, and develop a global partnership for development [1]. Women's empowerment and improvement in women's health are linked to the issue of poverty. The World Bank report of 2003 on poverty in Pakistan indicated that poverty exists in various forms in Pakistan and will continue to exist if various dimensions of poverty are not addressed as increase in income alone will not help to reduce or eliminate it.

It is known that poverty is a feature of rural and semi-rural areas in Pakistan, compared to urban areas. Furthermore, poverty affects women in Pakistan through low income and vulnerability to gender-related non-income factors [2-5]. Women usually do not earn direct income and household income is low in rural and semi-rural areas and is associated with poor health status. In developing countries like Pakistan, human development indices are in fact largely dependent on women's health and socioeconomic status [6] and the intrahousehold status of women is related to food security, particularly for children [7].

Low educational status of women is the strongest predictor of poverty and women in rural and semi-rural locations are not literate [8]. Poverty and socioeconomic disadvantage to women leads to environmental exposures that may increase their risk of nutritional deficiencies, adverse reproductive outcomes and poor health status [8-10].
Along with under-nutrition, maternal health is affected by manual labour (getting water and fuel for their households) [11-14]. Moreover the fertility rates among such women are high. The high energy demands on poor women from their combined productive and reproductive roles together with under-nutrition thus have a substantial impact on their health. This is further compounded by poor health care.

Children born to underweight and stunted women are also likely to be underweight and stunted which will affect their future potential at the individual and community level, thus establishing a vicious cycle [4]. Overall $19 \%$ of the children born in Pakistan are of low birth weight (LBW) [15] (birth weight $<2500 \mathrm{~g}$ ), which leads to high infant morbidity and mortality [16-18]. LBW varies within subgroups of a population and is reported to be associated with low socioeconomic status, parity, poor nutritional status, anaemia, maternal infections, smoking, hypertension, inadequate antenatal care and rural settings $[8-10,14,19,20]$.

The serious implications for maternal and child health have been studied and reported on but there is less information on the maternal dimensions of poverty. To address the specific nature of such poverty, it is important to evaluate maternal characteristics related to poverty. Thus the main objective of this study was to evaluate the relationship of monthly household income with gravidity status and demographic, nutritional and social characteristics in women living in a semi-rural location in Pakistan with at least 1 child under 5 years of age.

\section{Methods}

\section{Study setting}

The study was conducted in a semi-rural area of District Malir, Rehri Goth and 
adjoining communities located about 25 miles from the city of Karachi, Pakistan. The area is spread over $3 \mathrm{~km}$ and has a population of 35000 . It lacks basic utilities, transportation and health services [21,22]. It has a rural health centre, and general clinics run by nongovernmental organizations (NGOs). The Departments of Pediatrics \& Child Health and Community Health Sciences have centre-based and outreach programmes for child health; in addition the Department of Community Health Sciences is involved in community-based developmental activities. These programmes are conducted with the support of a local community-based health management group. In this setting, participation from community residents is $100 \%$ as long as there has been mutual agreement with the community management group.

\section{Sample size}

Sample size was calculated using a correlation coefficient of at least 0.1 between monthly income and maternal gravidity (number of pregnancies), two-sided alpha of 0.05 and beta of 0.10 ; thus 1050 participants were required. The survey identified 1111 married women living in the study area with at least 1 child less than 5 years of age; hence data for all of them were analysed to determine the relationship between maternal characteristics and household (nuclear family) reported monthly income.

\section{Study participants}

All married women aged 15 to 45 years who delivered a singleton live birth during the years 2000 to 2002 were included; pregnancies were identified historically by houseto-house surveys in 2000-2002. This study was the first part of a study that was done to establish a historical cohort of women who delivered a singleton live infants during the years 2000-2002. This initial full survey of the study area was done from January to September 2005 to obtain complete house listings in order to assemble the cohort, whereby a map of the area was used to identify ever-married women with at least 1 child less than 5 years of age. In this survey participation was high.

\section{Interviews}

The survey and consent form were approved by the Institutional Review Board of the University of California (UC) at Davis and the Ethics Review Committee of the Aga Khan University, Pakistan. The author with a study team supervised the conduct of the survey. The study team consisted of 3 field supervisors and 7 field workers. Field supervisors were graduates and received training from the author about the manuals, key documents for the questionnaire, and anthropometric measurements. The author and field supervisors were certified to obtain consent after taking an online tutorial and quiz on the National Institute of Health website for research with human subject participation. Field workers were recruited from the area with the help of the local community management team and were trained for consent taking, conducting pilot and modified questionnaire interviews, and measuring participants' weight, height, mid-arm circumference and skin-fold thickness. After reading aloud the consent form, the women either signed the form or provided a thumb print if they were wiling to participate. Field workers conducted the interviews and measurements. Quality checks for missing values were made on a daily basis by field supervisors and corrected. The questionnaire was pilot tested on a sample of 30 women living in the area who had at least 1 child less than 5 years of age. The final questionnaire obtained information on demographic, socioeconomic, lifestyle, anthropometric and reproductive factors,

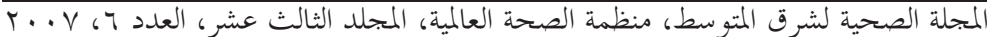


namely: participant's age, address, marital status, number of family members, number of persons living in the house, number of rooms in the house, and number of nuclear family members and rooms in use by them. Monthly household income was recorded in Pakistani rupees (Rs) (US\$ $1=$ Rs 60 at the time of survey). Literacy was categorized as ability to read and/or write and completed years of schooling. This variable was dichotomized as totally illiterate and literate. Husband's occupation was categorized as skilled (fisherman, tailor, driver and electrician) and unskilled (labourer and daily casual worker). Information was also obtained for the number of animals owned.

Information on smoking history and current use inside and outside the house was sought for the participant, spouse and other household members, including daily number of cigarettes smoked (local or available on the market) and duration of smoking. For participants, any use for cigarettes, beedi (a locally made cigarette from fragmented tobacco leaves rolled in dried tobacco leaves), and or huqqa (a traditional water pipe) was ascertained. Participants' use of chewing tobacco, including duration, frequency, and use with other substances, such as areca nuts and betel leaf, was also ascertained for current use and use during the past pregnancy. Tobacco use was dichotomized as tobacco user (cigarette, beeri, huqqa or chewing tobacco) and non-user. Tobacco use (as defined above) in the most recent past pregnancy was also recorded. Information was also sought on type of cooking fuel used, duration of cooking daily and amount of daytime rest per day. A structured grid was used to record history of all pregnancies by the year, and gravidity and parity were calculated for each participant.

Trained health workers used calibrated weighing scales to measure the women's weight in light clothing and bare feet in kilo- grams using a calibrated bathroom scale. A Lange skin caliper was used to measure left arm triceps skin-fold thickness. Standard measurement tapes were used by trained workers to measure participant's height, mid-arm, and mid-calf circumference in centimetres. Two measurements were taken for weight, height, skin-fold thickness, and mid-arm and mid-calf circumference. The first 50 measurements taken by health workers were standardized to those taken by the field supervisor and significant differences were not found.

\section{Statistical methods}

Continuous and ordinal variables were summarized first with descriptive statistics to check for distributions, and measures of central tendency were calculated. The Student $t$-test was used for comparing means for continuous variables. The chi-squared test for significance was used for comparing categorical covariates.

Self-reported household income was the dependent variable. Relationship with monthly income was determined for demographic, nutritional (anthropometric), reproductive, and non-income socioeconomic characteristics. The variable for income was dichotomized at the median level for comparison purposes. An index of crowding was calculated as the number of persons in the house divided by the number of rooms in the house; a similar index was calculated for the number of nuclear family members by number of rooms in use by the nuclear family. Gravidity was defined as the total number of pregnancies experienced by the woman irrespective of outcome; parity was the number of live births she had had. In multiple linear regression models, monthly income was regressed on demographic, nutritional (anthropometric), reproductive, and non-income socioeconomic variables that were associated with monthly income in 
the bivariate analyses. The distribution and linear association of continuous variables were checked prior to its inclusion in the multiple regression models; when required transformation or addition of a quadratic to achieve linear association was done.

Data were double-entered and validated in Epi-Info, version 6 and analyses were conducted using SPSS, version 12.00. The level of significance was taken as $P<0.05$.

\section{Results}

A total of 1111 mothers living in the area who had at least 1 child less than 5 years of age consented to participate in this interview-based survey. The median monthly income was Rs 3000 . Table 1 shows descriptive characteristics of the participants and comparison of these with the median income variable. Mean age of the participants was 29.28 [standard deviation (SD) 5.4] years, with a significant difference by income (Table 1). Mean crowding index for participant's nuclear family was 5.0 (SD 2.0 ) in the higher income group which was not significantly different from the lower income group [4.9 (SD 1.9)] $(P=0.10)$. Mean gravidity and parity were significantly greater for the higher income group compared to the lower income group (Table 1). Anthropometric indicators showed a better nutritional status for the higher income group compared to the lower income group, as expected (Table 1). Most of the women $(53.4 \%)$ in the higher income group used natural gas for cooking and most $(62.2 \%)$ in the lower income group uses wood $(P<$ 0.001 ). In addition, frequency of cooking was also greater in the high income group $(P=0.048)$. A significantly greater number of households possessed animals in the high income group (36\%) than the lower income group $(30 \%)(P=0.03)$.
Smoking in past pregnancy was greater in women in the higher income group (Table 1) but did not differ for reported current smoking status $(P=0.68)$. Current spousal smoking was greater in the higher income group $(21.6 \%)$ compared to the lower income group $(15.2 \%)(P=0.007)$; reported use by other family members was also greater in the higher income group $(11 \%)$ than the lower income group $(7.5 \%)$ $(P=0.06)$. More participants in the higher income group lived in houses made of a mix of straw and bricks and those made only with bricks than participants from the lower income group who lived in houses made of straw and a mix of straw and bricks (Table 1). The majority of the husbands were fisherman (77.7\%) which was included as a skilled profession; there were more fishermen in the lower income group $(80.7 \%)$ than the higher income group $(75.4 \%)(P=$ $0.04)$. Participants were asked about their current and past occupation, whether they were working in 2005 or had worked for money during the past pregnancy. Reported duration of daytime rest by the women ranged from none to 3 hours; women in the high income group had significantly longer daytime rest than the low income group.

Maternal age and gravidity were significantly correlated (Pearson correlation coefficient $=0.73, P<0.01$ ). Figure 1 shows the relationship between increasing maternal age and mean gravidity status by median income level; with consistently higher mean number of pregnancies in the high income group. In the linear regression model, age was positively associated with income; but after inclusion of gravidity the association was inverse. The self-reported monthly income was earned mainly by spouses, as women generally did not work other than do the housework. Monthly income was taken as a dependent variable in the linear regression model and was positively associated

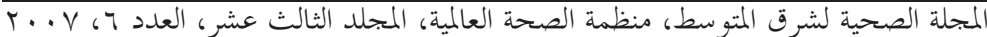




\begin{tabular}{|c|c|c|c|c|}
\hline Characteristic & $\begin{array}{c}\text { Overall } \\
(n=1111) \\
\text { Mean (SD) }\end{array}$ & $\begin{array}{c}\text { Monthly } \\
\text { income }>\text { median } \\
(n=630) \\
\text { Mean (SD) }\end{array}$ & $\begin{array}{c}\text { Monthly } \\
\text { income < median } \\
(n=481) \\
\text { Mean (SD) }\end{array}$ & $\begin{array}{c}P \text {-value } \\
\text { for income } \\
\text { groups }\end{array}$ \\
\hline Maternal age (years) & $29.28(5.4)$ & $29.44(5.7)$ & $29.08(5.9)$ & 0.001 \\
\hline No. of persons in house & $9.8(7.2)$ & $10.52(7.3)$ & $8.90(7.0)$ & 0.001 \\
\hline No. of rooms in house & $2.6(1.8)$ & $2.7(1.8)$ & $2.4(1.8)$ & 0.037 \\
\hline No. of persons in nuclear family & $5.8(2.3)$ & $6.0(2.4)$ & $5.4(1.9)$ & 0.001 \\
\hline $\begin{array}{l}\text { No. of rooms in use by the nuclear } \\
\text { family }\end{array}$ & $1.1(0.58)$ & $1.2(0.6)$ & $1.1(0.5)$ & 0.001 \\
\hline Maternal gravidity & $4.80(2.8)$ & $5.06(2.8)$ & $4.47(2.7)$ & 0.001 \\
\hline Maternal parity & $4.35(2.5)$ & $4.58(2.6)$ & $4.06(2.4)$ & 0.001 \\
\hline Maternal weight (kg) & $50.14(9.5)$ & $51.01(9.9)$ & $49.00(8.9)$ & 0.001 \\
\hline Maternal height $(\mathrm{cm})$ & $155.83(6.0)$ & $156.09(6.1)$ & $155.50(5.9)$ & 0.111 \\
\hline Body mass index $\left(\mathrm{kg} / \mathrm{m}^{2}\right)$ & $20.66(3.8)$ & $20.94(3.9)$ & $20.30(3.7)$ & 0.006 \\
\hline \multirow[t]{2}{*}{ Mid upper-arm circumference $(\mathrm{cm})$} & $24.50(3.1)$ & $24.82(3.2)$ & $24.09(3.04)$ & 0.001 \\
\hline & $\%$ & $\%$ & $\%$ & \\
\hline \multicolumn{5}{|l|}{ Type of house } \\
\hline Straw & 15.5 & 13.0 & 18.7 & \\
\hline Straw and brick mix & 65.5 & 66.8 & 63.8 & \\
\hline Brick & 19.0 & 20.2 & 17.5 & 0.028 \\
\hline \multicolumn{5}{|l|}{ Fuel used } \\
\hline Wood & 52.7 & 45.7 & 62.2 & \\
\hline Natural gas & 47.2 & 54.3 & 37.8 & 0.001 \\
\hline \multicolumn{5}{|l|}{ Cooking frequency: 3-4 times } \\
\hline per day & 71.4 & 76.7 & 81.8 & 0.048 \\
\hline Woman literate & 20 & 23.7 & 15.2 & 0.001 \\
\hline \multicolumn{5}{|l|}{ Husband's years of schooling } \\
\hline$\leq 5$ & 19.6 & 22.4 & 16.0 & 0.004 \\
\hline$>5$ & 9.3 & 10.5 & 7.7 & \\
\hline Husband's occupation: skilled & 77.7 & 75.4 & 80.7 & 0.042 \\
\hline $\begin{array}{l}\text { Tobacco use by woman in last } \\
\text { pregnancy }\end{array}$ & 24.9 & 27.9 & 21.0 & 0.010 \\
\hline Daytime rest $>60$ minutes & 48.1 & 44.5 & 54.3 & 0.002 \\
\hline
\end{tabular}

$S D=$ standard deviation.

with cooking food 3 to 4 times per day per day, maternal literacy, gravidity, paternal literacy, mid upper-arm circumference and number of persons living in the house; it was negatively associated with wood used as cooking fuel, spouse in skilled occupation, and crowding index (Table 2). 


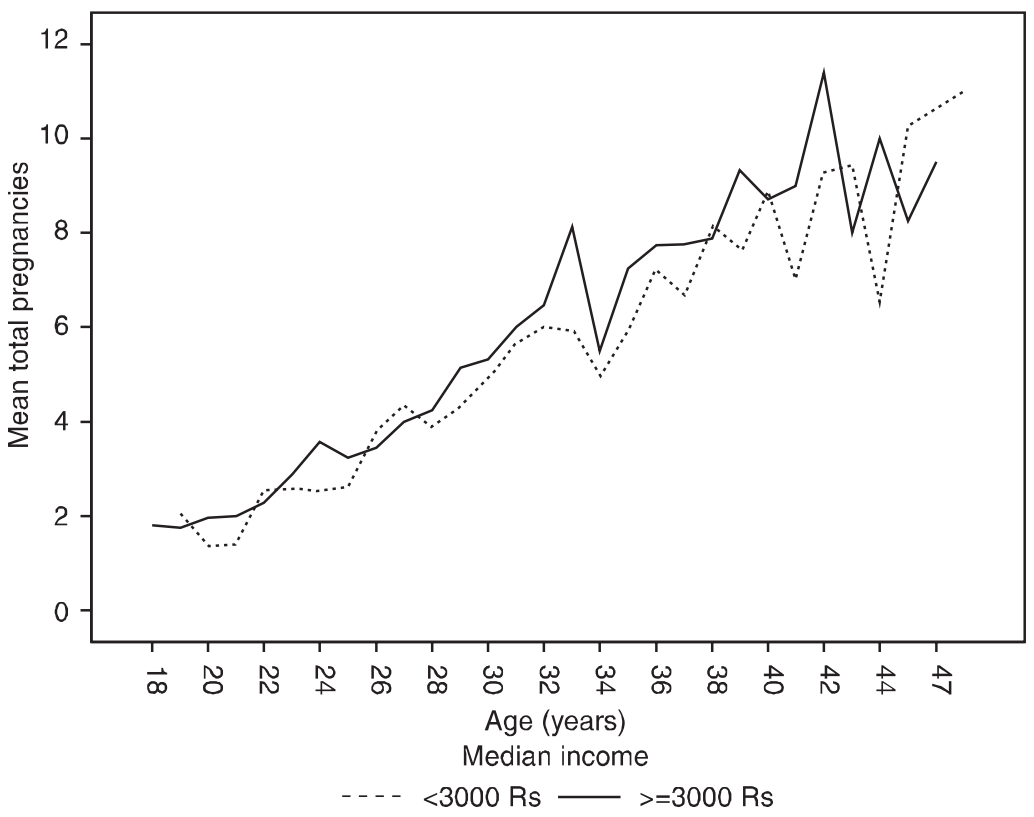

Figure 1 Relationship between increasing maternal age and mean gravidity by category of median income (US\$1 = Rs 60 at the time of the survey)

\section{Discussion}

This study provides valuable information on the relationship between income and non-income aspects of maternal poverty in a semi-rural and poor community. These non-income factors rely on income [2], and the purchasing capacity of participants is dependent on spousal earnings. Women's use of wood as a cooking fuel for example had a strong relationship with lower income and higher frequency of cooking per day with higher income. This is relevant to MDGs related to reducing hunger and eating the appropriate number of calories per day. In Pakistan about $53 \%$ of the population uses wood as a cooking fuel, and when combined with use of crop residues and biomass, this figure rises to $70 \%[12,13]$. In addition to being a correlate of poverty, fuel also contributes to indoor air pollution which women and children are likely to be more exposed to. The MDGs for environmental sustainability consider ambient air pollution, and rural families are vulnerable to indoor pollution if not to outside air pollution $[1,11]$.

Housing structure was not significantly associated with income in the final model. However, the crowding index (occupants per room) was, and this was independent of wood use and other variables.

Higher income was associated with increased gravidity; hence it is likely that increasing income could lead to larger families. This observation suggests strategic planning is needed to address this factor. Rural parts of Pakistan have higher fertility rates [5] and this setting is comparable to rural areas, and in spite of it being near to a large city, it has limited accessibility to civic amenities [22]. 
Table 2 Multiple linear regression model for reported monthly income (US\$) and maternal characteristics

\begin{tabular}{|c|c|c|c|c|}
\hline \multirow[t]{2}{*}{ Characteristic } & \multicolumn{2}{|c|}{ Coefficients } & \multirow[t]{2}{*}{$P$-value } & \multirow{2}{*}{$\begin{array}{l}95 \% \text { confidence } \\
\text { intervals for } B\end{array}$} \\
\hline & & SE & & \\
\hline Constant & 35.036 & 6.584 & 0.000 & 22.115 to 47.958 \\
\hline Total pregnancies & 3.045 & 0.916 & 0.001 & 1.248 to 4.842 \\
\hline Total pregnancies (square term)a & -0.173 & 0.066 & 0.009 & -0.303 to -0.044 \\
\hline Mid upper-arm circumference & 0.505 & 0.209 & 0.016 & 0.094 to 0.915 \\
\hline $\begin{array}{l}\text { Frequency of cooking per day: } 0=1-2 \text { times, } \\
\qquad 1=3-4 \text { times }\end{array}$ & 5.244 & 1.624 & 0.001 & 2.057 to 8.432 \\
\hline Woman literate: $0=$ no, $1=$ yes & 4.550 & 1.658 & 0.006 & 1.297 to 7.803 \\
\hline Husband literate: $0=$ no, $1=$ yes & 2.912 & 1.037 & 0.005 & 0.878 to 4.946 \\
\hline Cooking fuel used: $0=$ natural gas, $1=$ wood & -6.107 & 1.323 & 0.000 & -8.704 to -3.510 \\
\hline No. of persons living in house & 0.682 & 0.099 & 0.000 & 0.487 to 0.876 \\
\hline Occupation of spouse: $0=$ unskilled, $1=$ skilled & -3.425 & 1.592 & 0.032 & -6.549 to -0.301 \\
\hline $\begin{array}{l}\text { No. of nuclear family members/No. of rooms } \\
\text { occupied by them }\end{array}$ & -0.953 & 0.424 & 0.025 & -1.784 to -0.121 \\
\hline $\begin{array}{l}\text { Maternal use of cigarettes/beerilhuqqa: } 0=\text { no, } \\
1=\text { yes }\end{array}$ & 2.686 & 1.554 & 0.084 & -0.363 to 5.735 \\
\hline Daytime rest $>60$ minutes & -2.208 & 1.321 & 0.095 & -4.800 to 0.384 \\
\hline Age (years) & -0.267 & 0.161 & 0.097 & -0.582 to 0.048 \\
\hline
\end{tabular}

a The relationship of number of pregnancies reported by participants was positively associated with monthly income; but at the level of a very large number of pregnancies this relationship was negative; hence to make the relationship linear and to stabilize the residuals, the square value was used; this helped to improve the fit of the model.

SE $=$ standard error.

It is well known that education is the strongest predictor of reduction in poverty, especially female education. Our study found a positive association between the education of both the woman and her husband and monthly income. It is reported that improvement in maternal education from none or less than primary level to completed primary level has led to a reduction in extreme poverty [8]; furthermore it is not only the female financial contribution that is important but networking with other people also has positive effects. Two types of networking namely bound and achieved were reported. Bound networking is with close relatives, mainly developed by females, that helps prevent the family from falling further into poverty. Achieved networking is developing networks at the individual level; this is largely done by males and is known to move the household out of poverty [8].

In the current study, higher-income participants had a greater number of people living in the house. There is a cultural norm for families to live together and it is possible that some economic gains occur in this situation. However, the higher crowding index, indicating less space per person, had a negative relationship with income as expected.

Skilled occupation of the spouse was associated with decreasing income in the final model. This is perplexing and the data do 
not provide a logical reason for this association. However, there are reports that many fishermen (defined as a skilled occupation) in this locality are in debt to the boat owner and this may be a possible explanation [21]. Alternatively, fishing may currently be facing problems whereby general unskilled labour can earn more than fishing. This could be associated with breeding season, environmental pollution, reasons related to net income for services and many other factors.

Maternal weight, body mass index and mid upper-arm circumference were associated with income; surprisingly, maternal height was not. Mid upper-arm circumference is a good indicator of protein reserves of a body and body mass index is a better indicator of obesity [23]. Among the nutritional indicators (weight, height, body mass index, mid upper-arm circumference) of participants, increasing mid upper-arm circumference was included in the model and was positively related to increasing income. However, the mean mid upper-arm circumference of participants in this study was at the lower end (10th percentile of standard values for age).

The final model of income in this study also showed nearly significant associations with maternal use of tobacco in the past pregnancy. This points towards increasing tobacco use in women, which was recently reported for rural areas of Pakistan [24]. Health education and other measures are required for its control.

The strength of this study lies in the large sample and evaluation of non-income dimensions of maternal poverty. Poverty is a complex condition and we found strong and at times unexpected relationships with income. One of the limitations of the study is that self-reported income cannot be checked and hence is not the most valid of measurements. The relationship of skilled occupation with lower income is perhaps unusual but it is possible that it exists in some population groups. Hence economic growth schemes must consider this in their strategies and evaluation. Similarly does the frequency of cooking reflect how often a family eats? Perhaps, but as conditions for storing cooked food are poor in the community, this cannot be concluded without further evaluation.

Income is dependent on non-income factors such as literacy, and the nutritional and reproductive health status of women and these must be addressed to achieve the MDGs for health. However, reduction in poverty by increasing income may not directly lead to improvement in non-income indicators and relevant concurrent strategies need to be formulated for social problems that may arise, such as increasing gravidity (with consequent maternal morbidity and mortality), tobacco use, and the age cohort effects related to those who have low literacy levels but contribute to indicators of the human development index.

\section{Acknowledgements}

I am thankful to Dr Zulfiqar Bhutta, Department of Paediatrics and Child Health, Aga Khan University, Dr Kenneth H. Brown, Programme in International Nutrition, University of California at Davis and Dr Ellen B. Gold, Department of Public Health Sciences, University of California at Davis for their review of the design of the survey instrument. The financial support of the $\mathrm{Na}$ tional Institute of Health, USA is gratefully acknowledged (NIH Grant number 5R03 ES13159-2). 


\section{References}

1. Planning Commission Center for Research on Poverty Reduction and Income. Pakistan millennium development goals report 2005. Islamabad, Government of Pakistan, 2005.

2. Poverty in Pakistan. Issues, causes, and institutional responses. Islamabad, Asian Development Bank, 2002 (http://www. adb.org/documents/reports/poverty_pak/ poverty.pdf, accessed 2 July 2007)

3. Grosse M, Harttgen K, Klasen S. Measuring pro-poor progress towards the nonincome millennium development goals. Helsinki, UNU World Institute of Development Economics Research (UNU-WIDER), 2006 (Research paper No. 2006/38) (http://www.wider.unu.edu/publications/ rps/rps2006/rp2006-38.pdf, accessed 2 July 2007).

4. Kramer MS et al. Socioeconomic disparities in pregnancy outcome; why do the poor fare so poorly? Pediatric and perinatal epidemiology, 2000, 14:194-210.

5. Pakistan Demographic and Health Survey (PDHS) 1990/1991. Islamabad, Pakistan, National Institute of Population Studies; Columbia, Maryland, Macro International Inc., 1992.

6. Human development report 2006. Human development indicators. Country fact sheets - Pakistan (http://hdr.undp. org/hdr2006/statistics/countries/country fact_sheets/cty_fs_PAK.html, accessed 2 July 2007).

7. Guha-Khasnobis B, Hazarika G. Women's status and children's food security in Pakistan. Helsinki, UNU World Institute of Development Economics Research (UNU-WIDER), 2006 (Discussion paper No. 2006/03) (http://www.wider.unu.edu/ publications/dps/dps2006/dp2006-03.pdf, accessed 2 July 2007).

8. Haddad L. Women's status: levels, determinants, consequences for malnutrition, interventions, and policy. Asian development review, 1999, 17(1,2):96-131.

9. Fikree FF et al. Maternal mortality in different Pakistani sites: ratios, clinical causes and determinants. Acta obstetricia et gynecologica Scandinavica, 1997, 76(7):637-45.

10. Midhet F, Becker S, Berendes HW. Contextual determinants of maternal mortality in rural Pakistan. Social science and medicine, 1998, 46(12):1587-98.

11. Siddiqui $A R$ et al. Eye and respiratory symptoms among women exposed to wood smoke emitted from indoor cooking: A study from southern Pakistan. Journal of international energy initiative; energy for sustainable development, 2005, IX(3):58-66.

12. Situation analyses of household energy use and indoor air pollution in Pakistan. Geneva, World Health Organization, 2005 (Discussion papers on child health) (WHO/FCH/CAH/05.06 2005).

13. Rehfuess E, Mehta S, Prüss-Üstün A. Assessing household solid fuel use: multiple implications for the millennium development goals. Environmental health perspectives, 2006, 114(3):373-8.

14. Butt MA. Women's health problems in Pakistan. Middle East journal of family medicine, 2004, 2(2) (http://mejfm.com/ journal/oct03/Women.pdf, accessed 17 July 2007).

15. State of the world's children 2006: Excluded and invisible. New York, United Nations Children's Fund, 2006.

16. Akram DS, Arif F. Ponderal index of LBW babies - a hospital based study. Journal of the Pakistan Medical Association, 2005, 55(6):229-31.

17. Fikree FF, Rahbar MH, Berendes HW. Risk factors for stunting and wasting at age six, twelve, and twenty four months in 
squatter children of Pakistan. Journal of the Pakistan Medical Association, 2000, 50(10):341-8.

18. Tripathy $R$ et al. Physical status of newborns and neonatal outcome. Indian journal of pediatrics, 2002, 69(12):1041-5.

19. Lindley AA et al. Maternal cigarette smoking during pregnancy and infant ponderal index at birth in the Swedish Medical Birth Register, 1991-1992. American journal of public health, 2000, 90(3):420-3.

20. Gupta PC, Sreevidya S. Smokeless tobacco use, birth weight, and gestational age: population based, prospective cohort study of 1217 women in Mumbai, India. British medical journal, 2004, 328(7455):1538.

21. Hasan A. The unplanned revolution. Observations on the process of socioeco- nomic change in Pakistan. Karachi, City Press, 2002.

22. Regional technical assistance for coastal and marine resources management and poverty reduction in south Asia (ADB Reta 5974). Poverty and environment Nexus study: Rehri Mian, Korangi Creek area, Pakistan Component, Pakistan. Asian Development Bank; IUCN - World Conservation Union Pakistan, 2003 (http:// iczm-sa.iucnp.org/pakistan/pdf/pov-envnexp.PDF, accessed 2 July 2007).

23. Gibson SR. Principles of nutrition assessment. Oxford, Oxford University Press, 1990.

24. Khan I, Siddiqui MS. Trends and pattern of tobacco consumption in rural women of Pakistan. Pakistan Armed Forces medical journal, 2002, 52(2):208-12.

\section{World Health Report 2006}

The World Health Report 2006 - working together for health, available in English, French, Spanish and Portuguese, contains an expert assessment of the current crisis in the global health workforce and ambitious proposals to tackle it over the next ten years, starting immediately. The report reveals an estimated shortage of almost 4.3 million doctors, midwives, nurses and support workers worldwide. The shortage is most severe in the poorest countries, especially in subSaharan Africa, where health workers are most needed. Focusing on all stages of the health workers' career lifespan from entry to health training, to job recruitment through to retirement, the report lays out a ten-year action plan in which countries can build their health workforces, with the support of global partners.

The report can be downloaded at: http://www.who.int/whr/2006/en/

المجلة الصحية لشرق المتو سط، منظمة الصحة العالمية، المجلد الثالث عشر، العدد Y، V... 